ORIGINAL ARTICLE

\title{
The Effect of 8 Weeks of Zumba Exercise on Flexbılity and Some Strength Parameters in Women Aged 25-45
}

MEHMET MURAT BEYAZ1 ${ }^{1}$ GÖKÇE OKTAY²

${ }^{1}$ Assistant Professor, School of Physical Education and Sport, Istanbul Gelişim University, Istanbul, Turkey https://orcid.org/0000-00026254-5220

${ }^{2}$ Lecturrer, School of Physical Education and Sport, Istanbul Gelişim University, Istanbul, Turkey https://orcid.org/0000-0001-6225-2332

Corresponding author: Gökçe Oktay, Email: goktay@gelisim.edu.tr

\begin{abstract}
The aim of this study is to examine the effects of 6 -week Zumba exercises on flexibility, leg strength, back strength and muscular endurance parameters in women aged 25-45. The research group consists of a total of $(n=20)$ women, $(n=10)$ in the experimental group and $(n=10)$ in the control group, between the ages of 25-45 living in Istanbul. The participants in the experimental group were given 60 minutes of Zumba exercises 3 days a week for 6 weeks, and sit-reach, 1-minute sit-up and strength test measurements were made to the participants before and after the exercise program. Participants in the control group were not included in any exercise program. As a result of the analysis, it was determined that there was a statistically significant difference between the participants' flexibility, leg strength, back strength and muscular endurance values between the pre-test and posttest within the group $(p<0.05)$. In addition, there was no significant difference between the pre-test and post-test values between the groups $(p<0.05)$. In conclusion; It was determined that zumba exercises applied to the experimental group did not have a significant effect on flexibility, muscular endurance and back strength. In the leg strength parameter, the effect of zumba exercises applied to the experimental group on leg strength was found to be significant at a rate of $34 \%$. In the light of these data, it was concluded that zumba exercises performed in sedentary women have a positive effect on lower extremity strength.

Keywords: Zumba Fitness, Exercise, Women and Exercise
\end{abstract}

\section{INTRODUCTION}

Health behavior is one of the behaviors that an individual implements to lead a healthy life ${ }^{1}$. Today, exercise is considered as one of the basic principles of a healthy life. A healthy life with exercise is only possible if exercise programs are made relevant to the goal. In this sense, exercise protocols should be planned for different age groups and gender ${ }^{2}$. In the formation of a healthy society in a country and in raising healthy generations, the place and role of mother and woman in society is big $^{3}$. However, women devote most of their time to home and business life, and are pressured to fulfill the roles imposed by society. Although some women find it difficult to spare time for themselves in the free time left over from home and work life, it is inevitable that they are motivated in line with aims for certain goals within the framework of their quality of life ${ }^{4}$.

It is known that women have recently turned to exercise for both weight control and healthy living. Along with the tendency of women to different sports branches, it has brought with it many unknown data about women ${ }^{5}$. Cardio exercises are recommended for weight control, and zumba fitness exercises come to the foreground since they are more fun than these exercises.

Originating in Colombia, Zumba Fitness was created as a Latin-inspired dance fitness program that combines various dance elements with music as a method of engaging in aerobic exercise in preference to running or cycling. The exercises are combined with the basic steps and basic aerobic movements of other Latin dances such as merengue, salsa, samba, cumbia, and at the same time, the content is enriched with dances such as hip-hop dance and African dances ${ }^{6}$. Zumba exercises also include strength, balance and endurance training, and therefore, it has received increasing attention in the fitness industry in recent years ${ }^{7}$.
Recent studies using zumba fitness, a different type of Latin-based dance, have found that this type of exercise improves physical fitness and general health in adult women $8,9,10,11$. Findings from scientific research on Zumba fitness have great importance at this point. However, studies on the health-related physical fitness elements of zumba exercises in Turkey seem to be insufficient. Within the framework of the current potential of Zumba exercises, the effect on the physical condition of women between the ages of 25-45 who are in a sedentary life arouses curiosity. Therefore, the aim of this study is to examine the effects of 6-week zumba exercises on flexibility, leg strength, back strength and muscular endurance parameters in women aged 25-45.

\section{MATERIAL AND METHOD}

Pattern of the Research: In line with the purpose of the study, the research method was determined as a quasiexperimental design with pre-test post-test experimentcontrol group aiming to determine the cause and effect relationship between the variables ${ }^{12}$. Sit-reach (flexibility), 1-minute sit-ups (muscular endurance) and strength tests were applied to the participants.

Research Group: The research group consists of volunteer female participants $(n=20)$, aged between 25-45, living in Istanbul and having no health problems. Participants were randomly divided into experimental $(n=10)$ and control $(n=10)$ groups using the envelope method. The participants in the experimental group were given 60 minutes of Zumba exercises 3 days a week for 6 weeks, and measurements were made the day before the exercise program started and the day after the exercise program was finished. Participants in the control group were not included in any exercise program. 
Data collection tools:

Sit-Reach test: Sit-reach test was used to measure flexibility. The subject sitting in front of a box with dimensions of $32 \mathrm{~cm}$ high, $45 \mathrm{~cm}$ wide and $35 \mathrm{~cm}$ long tries to take the bar on the box as far as she can reach by moving it with both hands after leaning her bare feet on the inner surface of the box ${ }^{13}$. The test was repeated 3 times and the best value in $\mathrm{cm}$ was recorded on the data sheet.

1 Minute Sit-Up test: In the sit-up test; Subjects were made to do sit-ups as much as they could for 1 minute with the start command while lying on their back, knees bent at 90 degrees, hands on the back of the neck and soles of the feet in contact with the ground. During the sit-ups, the feet were held so that the contact of the feet from the ground was not broken ${ }^{14}$. The number of sit-ups made at the end of the session was recorded in the information form.

Strength test: The test was performed using a model 23527-3 back and leg (backlift) dynamometer manufactured by Lafeyette Instrument Company. While evaluating the leg strength, the participants were made to pull the dynamometer bar upwards with the support of their legs, after placing their feet with the knees bent, while the arms were in a straight and upright position ${ }^{15}$.

When assessing the back strength, after the participants placed their feet, the arms and legs were straight and tense, while the body was bent, the dynamometer bar was pulled upwards with the highest back strength. This application was repeated twice and the best grade was recorded in the information form in $\mathrm{kg}^{15}$.

Exercise Program: Different zumba exercise choreographies were applied to the participants in the experimental group, accompanied by 60 minutes of music, 3 days a week for 6 weeks. There are 8-10 different choreographies in the exercise program. The intensity of the exercise was determined as $50-60 \%$. Each music lasted 3-5 minutes, with a rest of $15-30$ seconds in between.

Table 1. Weekly Exercise Program Example

\begin{tabular}{|ll|l|l|l|l|}
\hline & & Exercise Duration & $\begin{array}{l}\text { Number of applied } \\
\text { choreographies }\end{array}$ & $\begin{array}{l}\text { Exercise } \\
\text { Intensity }\end{array}$ & Resting Time \\
\hline 1. & Day & $\begin{array}{l}60 \text { minutes } \\
(10 \text { min warm up, } 45 \text { min main part, } 5 \text { min cooling down })\end{array}$ & $8-10$ & $\% 50-60$ & $15-30 \mathrm{sec}$ \\
\hline 2. & Day & $\begin{array}{l}60 \text { minutes } \\
(10 \text { min warm up, } 45 \text { min main part, } 5 \text { min cooling down })\end{array}$ & $8-10$ & $\% 50-60$ & $15-30 \mathrm{sec}$ \\
\hline 3. & Day & $\begin{array}{l}60 \text { minutes } \\
(10 \text { min warm up, } 45 \text { min main part, } 5 \text { min cooling down })\end{array}$ & $8-10$ & $\% 50-60$ & $15-30 \mathrm{sec}$ \\
\hline
\end{tabular}

\section{RESULTS}

Table 1. Pre- and Post-Test Values of Participants' Leg Strength Measurements

\begin{tabular}{|c|c|c|c|c|c|c|c|}
\hline \multirow{2}{*}{ Parameters } & \multirow{2}{*}{ Groups } & \multirow{2}{*}{$\mathrm{N}$} & Pre test & Post test & \multirow[b]{2}{*}{$\mathrm{F}$} & \multirow[b]{2}{*}{${ }^{*} p$} & \multirow[b]{2}{*}{$\mathrm{\chi}_{2}$} \\
\hline & & & $\mathrm{X} \pm$ Ss & $\mathrm{X} \pm \mathrm{Ss}$ & & & \\
\hline \multirow{4}{*}{ Leg Strength } & Experimental & 10 & $59.00 \pm 12.20$ & $78.00 \pm 11.59$ & \multirow{2}{*}{1.955} & \multirow[b]{2}{*}{.179} & \multirow[b]{2}{*}{.098} \\
\hline & Control & 10 & $57.00 \pm 21.37$ & $59.30 \pm 22.44$ & & & \\
\hline & Total & 20 & $58.00 \pm 16.96$ & $68.65 \pm 19.85$ & \multirow{2}{*}{\multicolumn{3}{|c|}{${ }^{\star \star \star} \mathrm{F}: 9.415, \mathrm{p}: .007, \mathrm{Q}_{2}: .343$}} \\
\hline & & & \multicolumn{2}{|c|}{${ }^{* \star} \mathrm{F}: 15.315, \mathrm{p}: .001,2_{2}: .460$} & & & \\
\hline
\end{tabular}

1: Experimental group, 2: Control group, ${ }^{\star}$ Comparison between groups (Tests of between-subjects effects), ${ }^{\star *} / n-g r o u p$ comparison (Tests of within-subjects effects, between pre and post test), ${ }^{\star * *}$ Interaction (Tests of within-subjescts effects, Time* group), $p=0.05$

As a result of the analysis, it was determined that there was a statistically significant difference between the participants' in-group pre-test and post-test $(p=.001)$. On the other hand, when the difference values between the groups were examined, it was seen that there was no significant difference between the values of the experimental group and the control group $(p=.179)$. When the interaction (time* group) values were examined, it was determined that the effect of the exercise program applied to the experimental group was statistically significant $(p=.007)$. When the eta values are examined, it can be said that the effect rate of the exercise program is around $34 \%$.

Table 2. Pre-test and post-test values of participants' flexibility measures

\begin{tabular}{|c|c|c|c|c|c|c|c|}
\hline \multirow{2}{*}{ Parameters } & \multirow{2}{*}{ Groups } & \multirow{2}{*}{$\mathrm{N}$} & Pre test & Post test & \multirow{2}{*}{$\mathrm{F}$} & \multirow{2}{*}{${ }^{*} p$} & \multirow{2}{*}{$\mathrm{\chi}_{2}$} \\
\hline & & & $\mathrm{X} \pm \mathrm{Ss}$ & $\mathrm{X} \pm \mathrm{Ss}$ & & & \\
\hline \multirow{4}{*}{ Flexibility } & Experimental & 10 & $30.80 \pm 5.81$ & $34.15 \pm 5.61$ & \multirow{2}{*}{.309} & \multirow{2}{*}{.585} & \multirow{2}{*}{.017} \\
\hline & Control & 10 & $32.85 \pm 6.98$ & $34.90 \pm 5.45$ & & & \\
\hline & Total & 20 & $31.82 \pm 6.34$ & $34.52 \pm 5.40$ & \multirow{2}{*}{\multicolumn{3}{|c|}{${ }^{* * \star F} \mathrm{~F}: .499, \mathrm{p}: .489, \mathrm{१}_{2}: .027$}} \\
\hline & & & \multicolumn{2}{|c|}{${ }^{* *} \mathrm{~F}: 8.612, \mathrm{p}: .009, \mathrm{Q}_{2}: 324$} & & & \\
\hline
\end{tabular}

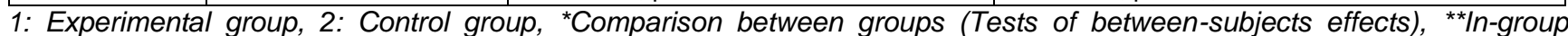
comparison (Tests of within-subjects effects, between pre and post test), ${ }^{\star * *}$ Interaction (Tests of within-subjescts effects, Time* group), $p=0.05$

As a result of the analysis, it was determined that there was a statistically significant difference between the participants' in-group pre-test and post-test $(\mathrm{p}=.009)$. On the other hand, when the difference values between the groups were examined, it was seen that there was no significant difference between the values of the experimental group and the 
control group $(p=.585)$. When the interaction (time*group) values were examined, it was seen that the effect of the exercise program applied to the experimental group was not statistically significant $(p=.489)$. When the eta values are examined, it can be said that the effect rate of the exercise program is around $1 \%$.

Table 3. Pre-test and post-test values of 1 minute sit-up measurements of the participants

\begin{tabular}{|c|c|c|c|c|c|c|c|}
\hline \multirow{2}{*}{ Parameters } & \multirow{2}{*}{ Groups } & \multirow{2}{*}{$\mathrm{N}$} & Pre test & Post test & \multirow{2}{*}{$\mathrm{F}$} & \multirow{2}{*}{${ }^{*} p$} & \multirow{2}{*}{$\mathrm{Q}_{2}$} \\
\hline & & & $\mathrm{X} \pm \mathrm{Ss}$ & $\mathrm{X} \pm \mathrm{Ss}$ & & & \\
\hline \multirow{3}{*}{$\begin{array}{l}1 \text { Minute Sit- } \\
\text { Up }\end{array}$} & Experimental & 10 & $34.80 \pm 10.43$ & $43.30 \pm 9.05$ & \multirow[t]{2}{*}{1.335} & \multirow{2}{*}{.263} & \multirow{2}{*}{.069} \\
\hline & $\begin{array}{l}\text { Control } \\
\text { Total }\end{array}$ & $\frac{10}{20}$ & $\frac{31.70 \pm 11.73}{33.25 \pm 10.92}$ & $\begin{array}{l}37.00 \pm 6.89 \\
40.15 \pm 8.47\end{array}$ & & & \\
\hline & & & \multicolumn{2}{|c|}{${ }^{* \star} \mathrm{F}: 21.041, \mathrm{p}: .000, \mathrm{Q}_{2}: .539$} & \multicolumn{3}{|c|}{${ }^{\star \star \star} \mathrm{F}: 1.131, \mathrm{p}: .302, \mathrm{Q}_{2}: .059$} \\
\hline
\end{tabular}

1: Experimental group, 2: Control group, ${ }^{*}$ Comparion between groups (Tests of between-subjects effects), ${ }^{* *} / n-g r o u p$ comparison (Tests of within-subjects effects, between pre and post test), ${ }^{\star * *}$ Interaction (Tests of within-subjescts effects, Time*group), $p=0.05$

As a result of the analysis, it was determined that there was a statistically significant difference between the participants' in-group pre-test and post-test $(p=.000)$. On the other hand, when the difference values between the groups were examined, it was seen that there was no significant difference between the values of the experimental group and the control group $(p=.263)$. When the interaction (time* ${ }^{*}$ roup) values were examined, it was seen that the effect of the exercise program applied to the experimental group was not statistically significant $(p=.302)$. When the eta values are examined, it can be said that the effect rate of the exercise program is around $1 \%$.

Table 4. Pre-test and post-test values of the participants' back measurements

\begin{tabular}{|c|c|c|c|c|c|c|c|}
\hline \multirow{2}{*}{ Parameters } & \multirow{2}{*}{ Groups } & \multirow{2}{*}{$\mathrm{N}$} & Pre test & Post test & \multirow{2}{*}{$\mathrm{F}$} & \multirow{2}{*}{${ }^{*} p$} & \multirow{2}{*}{$\mathrm{\Upsilon}_{2}$} \\
\hline & & & $\mathrm{X} \pm \mathrm{Ss}$ & $\mathrm{X} \pm \mathrm{Ss}$ & & & \\
\hline \multirow{4}{*}{ Back Strength } & Experimental & 10 & $62.50 \pm 15.13$ & $75.50 \pm 14.03$ & \multirow{2}{*}{2.065} & \multirow{2}{*}{.168} & \multirow{2}{*}{.103} \\
\hline & Control & 10 & $53.00 \pm 22.13$ & $62.00 \pm 20.84$ & & & \\
\hline & Total & 20 & $57.75 \pm 19.08$ & $68.75 \pm 18.62$ & \multirow{2}{*}{\multicolumn{3}{|c|}{${ }^{* * *} \mathrm{~F}: 1.152, \mathrm{p}: .297, \mathrm{Z}_{2}: .060$}} \\
\hline & & & \multicolumn{2}{|c|}{${ }^{* *} \mathrm{~F}: 34.848, \mathrm{p}: .000, \mathrm{Q}_{2}: .659$} & & & \\
\hline
\end{tabular}

1: Experimental group, 2: Control group, ${ }^{\star}$ Comparison between groups (Tests of between-subjects effects), ${ }^{\star *} / n-g r o u p$ comparison (Tests of within-subjects effects, between pre and post test), ${ }^{\star * *}$ Interaction (Tests of within-subjescts effects, Time*group), $p=0.05$

As a result of the analysis, it was determined that there was a statistically significant difference between the participants' in-group pre-test and post-test $(p=.000)$. On the other hand, when the difference values between the groups were examined, it was seen that there was no significant difference between the values of the experimental group and the control group $(p=.168)$. When the interaction (time* group) values were examined, it was seen that the effect of the exercise program applied to the experimental group was not statistically significant $(p=.297)$. When the eta values are examined, it can be said that the effect rate of the exercise program is around $1 \%$.

\section{DISCUSSION and CONCLUSION}

It was determined that the flexibility pre-test average of the sedentary women in the experimental group was $30.80 \pm 5.81$, the leg pre-test average was $59.00 \pm 12.20$, the back pre-test average was $62.50 \pm 15.13$, the 1-minute sit-up pre-test average was $34.80 \pm 10.43$. It was determined that the flexibility post-test average was $34.15 \pm 5.61$, the leg post-test average was $78.00 \pm 11.59$, the back post-test average was $75.50 \pm 14.03$, the 1 -minute sit-up post-test average was $43.30 \pm 9.05$.

Flexibility, leg strength, back strength and muscular endurance measurements of sedentary women in the research group were evaluated before and after 6-week zumba exercises. As a result of the analysis, it was determined that there was a statistically significant difference between the participants' flexibility, leg strength, back strength and muscular endurance values between the pre-test and post-test within the group. In addition, there was no significant difference between the pre-test and post-test values between the groups.

In a similar study, Donath et al. (2014) stated that there is a difference between the sit-reach test values before and after zumba exercises ${ }^{7}$. When the literature is examined; In the study titled "Investigation of the Effects of 8-Week Zumba and Step-Aerobic Exercises Applied to

Women on Health-Related Physical Fitness Elements" by Saygın et al. (2013), a statistically significant difference was found in the pre- and post-test flexibility values $^{16}$. In another study titled "The Effect of Tae-Bo and Pilates Exercises on Physical Fitness Parameters" by Doğan (2018), she stated that Tae-Bo and Pilates exercises improve flexibility values ${ }^{17}$. Studies in the literature support our research findings in general. Therefore, it can be said that zumba exercises are an important factor in the development of flexibility values of sedentary women.

It is seen that there are studies that are similar to our research findings as well as studies that are not in the same direction, in which the effects of zumba and fitness exercises for sedentary women on leg strength are evaluated. This may be due to the differences in the research group or the content of the applied choreography. In the study of Oktay (2015) "Investigation of the Effects of 8-Week Zumba and Step-Aerobics Exercises on Health- 
Mehmet Murat Beyaz, Gökçe Oktay

Related Physical Fitness Elements in Women", no significant difference was found in leg strength values ${ }^{18}$. In the study titled "The Benefits of Zumba Fitness Exercises on Health-Related Physical Fitness Elements in Sedentary Women" by Barranco-Ruiz et al. (2019), it was stated that there was a significant difference between the leg strength pre-post test values ${ }^{19}$. In a similar study, Gucluover (2020) found a significant difference between lower extremity values before and after 8-week zumba exercises ${ }^{20}$. In the study conducted by Ağaoğlu (2019), a significant difference was observed between the leg strength values of the zumba group participating in the research ${ }^{21}$. In another study, Chavarrias et al. (2019) stated that there was a significant difference in leg strength values ${ }^{22}$.

When the effects of Zumba exercises on the back strength and muscular endurance of women were evaluated, it was stated that there was a significant difference between the pre-post-test values of back strength in the study conducted by Oktay (2015), which was in parallel with our research findings in the literature ${ }^{23}$. Again, in the study of Delextrat (2016), it was determined that there was an $18.6 \%$ increase in strength values between pre-post test values ${ }^{24}$. Barranco-Ruiz et al. (2019) found a significant difference in muscle mass in a similar study named "The Effect of Two Choreographed Fitness Group Study on Body Composition, Cardiovascular and Metabolic Health of Sedentary Female Workers"19. When we examine the literature; In the study titled "The Effect of Tae-Bo and Pilates Exercises on Physical Fitness Parameters" conducted by Doğan (2018), a significant difference was found in the pre-post test values of the 30second sit-up test ${ }^{17}$. Mazlan (2018) stated in his research that the 24-week aboxercise program of male participants aged 34-39 was effective on the level of muscular endurance $^{25}$. Ozdemir et al. (2014), In the study on the "Effects of the 8-Week Exercise Program on the Reaction Time of Children with Down Syndrome", it was determined that the exercise contributed to the positive development of the reaction times of the participants ${ }^{26}$. When we examine the literature; it was stated that there was no significant difference in the muscular endurance values of the participants in the study titled "Effects of the 8-Week Aerobic Dance Program on Health-Related Vitality in Patients with Schizophrenia" by Cheng et al. $(2018)^{27}$.

In Conclusion; In this study, which was conducted to examine the effect of 6 -week zumba exercises applied to sedentary women in the research group on muscular endurance, back strength, leg strength and flexibility parameters, it was determined that the effect of zumba exercises applied in the experimental group on flexibility, muscular endurance and back strength was not significantly different by $1 \%$. In the leg strength parameter, the effect of zumba exercises applied to the experimental group on leg strength was found to be significant at a rate of $34 \%$. This shows that in the study, zumba exercises have a higher effect on the leg strength of the participants. Especially due to the different jumping and acceleration situations of zumba exercises, the muscle groups in the lower extremities are exposed to more load, and the formation of eccentric and concentric contraction situations supports this result. In the study that was done last, it was concluded that zumba exercises performed in sedentary women have a positive effect on lower extremity strength.

\section{REFERENCES}

1. Karaca., Y., Gündoğdu., C. \& Kızılkaya Namlı., A. (2019). "Evaluation of Healthy Living Style Behaviours of High School Students (Adiyaman City Example)", International Social Sciences Studies Journal, 5(36):2920-2927.

2. Kurt, S., Hazar, S., İbiş, S., Albay, B., \& Kurt, Y. (2010). Evaluation of thee ffects of eight-week step-aerobic exercise on some physical fitness parameters in middle-aged sedentary women. International Journal of Human Sciences, 7(1), 665-674.

3. Kutlu, M. Y. (2013). Women's Health Diseases and Care. Palme Publishing, renewed 2nd Edition, Ankara.

4. Karakaş, G., Kolayiş, İ. E., \& Eskiler, E. (2015). Investigation of exercise motivation of women participating in swimming exercise. Proceedings of the III Recreation Research Congress, Eskisehir, Turkey, 5-7.

5. Cihan H. (2007) WomenAnd Sports, www.hamitcihan.com/dizin. asp?id=129\&t=1.

6. Ljubojević, A., Jakovljević, V., \&Popržen, M. (2014). Effects of zumba fitness program on body composition of women. Sportlogia, 10(1), 29-33.

7. Donath, L., Roth, R., Hohn, Y., Zahner, L., \&Faude, O. (2014). Thee ffects of Zumba training on cardiovascular and neuro muscular function in female college students. European Journal of Sport Science, 14(6), 569577.

8. Domene, P. A., Moir, H. J., Pummell, E., Knox, A., \&Easton, C. (2016). The health-enhancing efficacy of Zumba® fitness: An 8-week randomised controlled study. Journal of sports sciences, 34(15), 1396-1404.

9. Krishnan, S., Tokar, TN, Boylan, MM, Griffin, K., Feng, D., Mcmurry, L.,\& Cooper, JA (2015). Zumba® Dance Improves Health in Overweight / Obeseor Type 2 Diabetic Women. American Journal of Health Behavior, 39 (1), 109-120.

10. Araneta, MR ve Tanori, D. (2014). Benefits of Zumba Fitness $\AA$ among sedentary adults with components of the metabolic syndrome: a pilot study. The Journal of Sports Medicine and Physical Fitness, 55 (10), 1227-1233

11. Inouye, J., Nichols, A., Maskarinec, G., \&Tseng, C. W. (2013). A survey of musculo skeletal injuries associated with Zumba. Hawai'i Journal of Medicine \& Public Health, 72(12), 433.

12. Büyüköztürk, S. (2007). Handbook of Data Analysis for Social Sciences (8th Edition). Ankara: Pegem Publishing.

13. Aydın, M. (2019). Investigation of the Effect of FootballSpecific Functional Training on Physical Fitness in 11-13 Age Groups. (Unpublished Master Thesis). Aydın Adnan Menderes University/Health Sciences Institute, Aydın.

14. Güler, D., \& Günay, M. (2004). Evaluation of the Physical Fitness of 8-10 Age Group Boys with Aahperd Test Battery. Gazi Journal of Physical Education and Sport Sciences, 9(2), 59-68.

15. Turna, B., Gençtürk, B., \& Bulduk, Y. (2019). An Investigation of The Effect of Post-Activation Potentiation on Some Performance Parameters in Young Male Soccer Players. Mediterranean Journal of Humanities, IX/1 (2019), 335-347.

16. Saygın, Ö., Oktay, G., \& Ceylan, H. İ. (2016). Examınıng The Effects Of 8-Week Zumba And Step-Aerobıc Exercıses On Health-Related Physical Fitness Factors In Women. SSTB International Refereed, Academic Journal of Sports, Health\&Medical Sciences, (19).

17. Doğan, E. (2018). TheEffect of Tae-BoandPilatesExercises on Physical Fitness Parameters, (Unpublished Master Thesis). Selçuk University/Health Sciences Institute, Konya. 
18. Oktay, G. (2015). Investigation of the effect of 8-Week Zumba and Step-Aerobic Exercises on Health-Related Physical Fitness Elements in women, (Unpublished Master Thesis). Muğla Sıtkı Koçman University/Health Sciences Institute, Muğla.

19. Barranco-Ruiz, Y., Ramírez-Vélez, R., Martínez-Amat, A., \& Villa-González, E. (2019). Effect of Two Choreographed Fitness Group-Workouts on the Body Composition, Cardiovascular and Metabolic Health of Sedentary Female Workers. International journal of Environmental Research and Public Health, 16 $\left.{ }^{2} 4\right)$, 4986.

20. Gucluover, A. (2020). The Effect Of 8-Week Zumba (R) Fitness On Body Composition Of Turkish Womens. Progress In Nutritıon, 22 (1).

21. Ağaoğlu, C. (2019) Investigation of the Effects of 8-Week Pilates, Zumba and Workout Exercises on Some Physical Fitness Parameters in Young Women, (Unpublished Master Thesis). Gazi University/ Health Sciences Institute, Ankara.

22. Chavarrias, M., Carlos-Vivas, J., Barrantes-Martín, B., \&Pérez-Gómez, J. (2019). Effects of 8-week of fitness classes on blood pressure, body composition, and physical fitness. The Journal of Sports Medicine and Physical Fitness, 59(12), 2066-2074.

23. Oktay, G. (2015). Investigation of theeffect of 8-Week Zumba and Step-Aerobic Exercises on Health-Related
Physical Fitness Elements in women, (Unpublished Master Thesis). Muğla Sıtkı Koçman University/Health Sciences Institute, Muğla.

24. Delextrat, AA, Warner, S., Graham, S. ve Neupert, E. (2016). An 8-Week Exercise Intervention Based on Zumba Improves Aerobic Fitness and Psychological Well-Being in Healthy Women Journal of Physical Activity and Health, 13 (2), 131-139.

25. Mazlan, i. (2018). The effects of mixedexercise (ABOXERCISE) on Cardiovascular endurance, muscular endurance and BMI level in 30- to 40-year-old obese males. Pertanika Journal of Social Science and Humanities, 26(3), $1519-1527$

26. Özdemir, M., Kaldıımcı, M.,llkım, M., Dinçer, N.\& Mızrak, O. (2014).The Effect of An 8-Week Physical Exercise on Reaction Time of Special Education Students With Down Syndrome Aged Between 11 And 14. Ataturk University Journal of Physical Education and Sport Sciences, 16(4), 917.

27. Cheng, S. L., Sun, H. F., \&Yeh, M. L. (2017). Effects of an 8week aerobicdance program on health-related fitness in patients with schizophrenia. journal of Nursing Research, 25(6), 429-435. 